\title{
Late Stages of Phase Separation in a Binary Polymer Blend Studied by Rheology, Optical and Electron Microscopy, and Solid State NMR
}

\author{
Ioannis S. Polios, ${ }^{\dagger}$ Maria Soliman, ${ }^{\dagger, \S}$ Chin Lee, ${ }^{\dagger}$ Samuel P. Gido, ${ }^{\ddagger}$ \\ Klaus Schmidt-Rohr, ${ }^{*, \pm}$ and H. Henning Winter*,t,
}

Department of Chemical Engineering and Department of Polymer Science and Engineering, University of Massachusetts, Amherst, Massachusetts 01003

Received J anuary 29, 1997; Revised Manuscript Received May 5, $1997^{\circledR}$

\begin{abstract}
The relation between rheology and the time dependent morphology of a phase-separating binary blend of polystyrene and poly(vinyl methyl ether) was investigated by heating a sample from the single-phase (at $90^{\circ} \mathrm{C}$ ) into the two-phase regime (at $124^{\circ} \mathrm{C}, 16 \mathrm{~K}$ above the LCST) and maintaining its temperature there while measuring the evolution of the dynamic moduli $G^{\prime}$ and $G^{\prime \prime}$. Morphological changes occurred slowly so that there was sufficient time to cycle the dynamic mechanical measurements repeatedly over five decades in frequency. The morphology was observed on length scal es from $1 \mathrm{~mm}$ down to $1 \mathrm{~nm}$ by conventional optical microscopy combined with digital image analysis, Hoffman modulation microscopy, TEM, and WISE NMR with spin diffusion. NMR shows that major compositional changes occur mostly in the first $20 \mathrm{~min}$ and then the composition remains constant at about 60:40 PS/PVME for the PS-rich matrix and 5:95 PS/PVME for the PVME-rich microdomains. The PVME-rich microdomains are separated by thin layers of the PS-rich phase which forms the matrix. On a larger scale, shape and geometry change during the entire experiment $(42 \mathrm{~h})$. The linear domain growth appears to be consistent with the theories of Siggia and Doi-Ohta. The initial increase of the dynamic moduli is attributed to the formation of highly interconnected PVME-rich and PS-rich phases during spinodal decomposition. The subsequent decrease of the values of the dynamic moduli is considered to be the result of the loss of the interconnectivity between the two phases due to the breakup of the PS-rich phase network and the coalescence of the PVME-rich domains.
\end{abstract}

\section{Introduction}

Most rheological studies of miscible polymer blends examine the single-phase regime.1,2 The rheological behavior of phase-separated blends and blends near the phase transition is not well-understood. Rheology is generally sensitive to morphological changes during phase separation, but the insufficient information on the morphology does not allow correlation between rheological and morphological data. A correlation between the evolution of the phase-separated morphology of a polystyrene (PS)/poly(vinyl methyl ether) (PVME) polymer blend and the evolution of its rheological behavior is presented in this paper. The dramatic changes in the morphology during the late stages of phase separation, including effects interpreted as "phase inversion", 3 have been characterized on length scales from $1 \mathrm{~mm}$ down to $1 \mathrm{~nm}$ by conventional optical microscopy, Hoffman modulation microscopy, TEM, and WISE NMR with spin diffusion.

The binary blend of PS/PVME is one of the moststudied miscible polymer blends, since it exhibits a lower critical solution temperature (LCST) within the experimental temperature window. The miscibilities of PS and PVME were demonstrated by the observations of a single $T_{g}$ at all compositions for temperatures below the LCST (about $100{ }^{\circ} \mathrm{C}$ ). 4,5

In 1974, Kwei, Nishi, and Roberts ${ }^{6}$ determined the composition of each phase-separated domain of a 50/50 PS/PVME blend by measuring the ${ }^{13} \mathrm{C}$ NMR spin-lattice relaxation time of single-phase and two-phase blends.

\footnotetext{
* To whom correspondence should be addressed.

† Department of Chemical Engineering.

‡ Department of Polymer Science and Engineering.

$\S$ Present Address: Central Laboratory, DSM, Geleen, The Netherlands.

${ }^{\otimes}$ Abstract published in Advance ACS Abstracts, J uly 1, 1997.
}

They observed a gradual change of concentration of PVME or PS in each phase during the early stages of the phase separation process and negative apparent diffusion coefficients, which clearly demonstrated the spinodal decomposition mechanism.

The effect of phase separation on the low-frequency dynamic mechanical behavior was determined ${ }^{7}$ by measuring the complex moduli $G^{\prime}$ and $G^{\prime \prime}$ at frequencies in the range $0.01-100 \mathrm{~s}^{-1}$ in PS/PVME blends containing $20 \%-60 \%$ polystyrene. For the $20 / 80$ and $40 / 60$ blends, the terminal zone was accessible and phase separation was accompanied by a large increase in both $\mathrm{G}^{\prime}$ and $\mathrm{G}^{\prime \prime}$. The complex modulus G* for the 40/60 PS/PVME blend at low frequency $(0.1 \mathrm{rad} / \mathrm{s})$ was found to increase slowly with time (on a time scale of $2 \mathrm{~h}$ ) for the samples annealed a few degrees bel ow the LCST while it was found to decrease slowly with time (on a time scale of 2 h) for the samples that were annealed $10-30 \mathrm{~K}$ above the LCST.

The phase behavior strongly depends on flow. Katsaros, Malone, and Winter ${ }^{8}$ demonstrated that either shear flow or extensional flow can suppress the phase separation at temperatures above the LCST or induce phase separation below the LCST (at high stress). These phenomena will not be discussed here, since we limit ourselves to small-strain experiments.

Katzen and Reich ${ }^{3}$ investigated a PS/PVME system with $M_{P S} / M_{P V M E} \cong 5$. They monitored the evolution of the phase-separated morphology by means of Nomarsky interferometry and found that it develops in a spinodal decomposition and then undergoes what they termed as a "phase inversion". During this phase inversion, one of the initially cocontinuous phases (developed during the spinodal decomposition) forms a continuous matrix phase which becomes the minority phase of the system after $1200 \mathrm{~s}$. The redistribution of the components between the two phases is considered the dominant 
factor for the failure of the simple scaling laws. ${ }^{9,10}$

The purpose of our study is to show how the rheological behavior of the phase-separated blend and its morphological behavior are closely related. Furthermore, we want to address the issues of the effects of segmental mobility on thetimescale of phase separation and search for a consistent mechanism of domain growth. We chosea 20/80 PS/PVME blend for the study, since its time dependent morphology evolves slowly and continuously. This allows us to address the interplay between the composition of the phase-separated domains, their size and shape, and their effect on the rheology.

\section{Experimental Section}

Materials and Sample Preparation. Polystyrene (Monsanto, Lustrex 101) with $M_{w}=260400$ and a polydispersity of 1.78 and PVME (Scientific Polymer Products) with $\mathrm{M}_{\mathrm{w}}=$ 87400 and a polydispersity of 1.49 were used to prepare the blend samples. The molecular weights were measured using GPC equipped with a light-scattering detector and calibrated with PS standards. The solvent for the GPC measurement was THF for both polymers. We chose to study a 20/80 PS/ PVME blend for which we were able to probe in the terminal zone with adequate torque values for rheometry at temperatures around $120{ }^{\circ} \mathrm{C}$, which is sufficiently far below the decomposition temperature of pure PVME (ca. $150^{\circ} \mathrm{C}$ ). Films of 20/80 PS/PVME were cast from toluene solutions at room temperature. The sheets for rheological measurements were cast from $30 \%$ solutions in tol uene on Tefl on-coated pans, and films for microscopy studies were cast from 10\% toluene solutions on glass slides. The solvent was evaporated by exposure to air at room temperature for $48 \mathrm{~h}$. The samples were then slowly dried under vacuum at $70{ }^{\circ} \mathrm{C}$ for 10 days to remove traces of moisture and toluene. Sheets for rheol ogical studies were approximately $1-1.5 \mathrm{~mm}$ in thickness, and films for microscopy studies were $25-30 \mu \mathrm{m}$ thick. This is considerably thicker than the $5-8 \mu \mathrm{m}$ thick films used by Reich and Cohen, ${ }^{11}$ who found a dependence of the phase behavior on film thickness and substrate.

The samples used for rheological measurements were heated under vacuum (so that oxidation is retarded) at the desired temperature in the two-phase region. Subsequently, they were quenched in a freezer so that morphological changes could no longer take place. We observed that a two-phase polymer blend that was kept in the two-phase region for at least 20 min, at a temperature approximately $15 \mathrm{~K}$ above the LCST, retains its morphological characteristics for at least 1 year at room temperature. Those phase-separated samples were used for NMR and TEM measurements.

Rheology. The rheological behavior of the system was studied using isothermal frequency sweeps over a long period of time. Samples were loaded into a Rheometrics RDS-7700 rheometer at $90{ }^{\circ} \mathrm{C}$ under dry nitrogen and equilibrated for at least $1 \mathrm{~h}$ prior to measurements. The measurement began by rapidly heating the sample to $124{ }^{\circ} \mathrm{C}$ and holding it at this temperature for $42 \mathrm{~h}$. Strain sweeps in the range $0.03-0.3$ shear strain, at frequencies of $0.1,1,10,100$, and $500 \mathrm{rad} / \mathrm{s}$, were used to determine the linear viscoelastic range of the material. The isothermal experiment (at $124{ }^{\circ} \mathrm{C}$ ) lasted for $42 \mathrm{~h}$, during which the probing frequencies were altered cyclically from 0.1 to $500 \mathrm{rad} / \mathrm{s}$. I n each measurement, it was possible to apply sufficient strain amplitudes (and still remain in the linear viscoelastic regime) to ensure adequate torque values. The data were analyzed using time-resolved rheometry software. ${ }^{12}$

Optical Microscopy. The $25 \mu \mathrm{m}$ thick films were covered with cover slips and placed on a Linkam hot stage at $90{ }^{\circ} \mathrm{C}$ under a blanket of dry nitrogen. The films were allowed to equilibrate at this temperature for at least $1 \mathrm{~h}$ before further heating. At this temperature, all the films were water-like clear, which shows that the blends were mixed at least on a length scale comparable to the wavelength of visible light. The temperature was subsequently increased to $124{ }^{\circ} \mathrm{C}$ and held constant within $\pm 0.1 \mathrm{~K}$ for the remainder of the experiment. Hoffman modulation contrast ${ }^{13}$ was used for two purposes: first, to observe the developing morphology during the phase separation and, second, to determine which phase (if any) forms the continuous matrix phase of the sample during the evolution of the morphology. The very fine structure of the early stages of phase separation (i.e. after 20 min from the onset of phase separation) could not be resolved with the lower magnification $(10 \times$ and $30 \times)$ H offman modulation objectives, but it was observable with conventional microscopy with a $50 x$ long working distance objective and a numerical aperture of 0.60 . In both cases, images were recorded by means of a camera equipped with a CCD detector. These were then digitized and stored for subsequent analysis.

Electron Microscopy. Ultrathin TEM sections with thicknesses of approximately $500 \AA$ were obtained by cryo-microtoming (using a diamond knife) the disk-shaped samples after annealing at $124{ }^{\circ} \mathrm{C}$ for the appropriate amount of time. The cutting was performed at a temperature of $-100^{\circ} \mathrm{C}$ to ensure that no alteration of the morphology takes place during cutting. The contrast between the phases in the PS/PVME system does not occur by diffraction or scattering because both phases are amorphous and the differences in atomic weight per unit volume are small. However, the polymers degrade selectively in the electron beam; ${ }^{14}$ the light regions are PVMErich (PVME due to the ether bond is more el ectronegative and absorbs electrons), and the dark regions are PS-rich. The images were obtained with a J EOL-100CX electron microscope, using an accel erating voltage of $100 \mathrm{kV}$, for which the contrast between the phases developed in approximately 10-20 s and then did not change significantly over $30 \mathrm{~min}$.

Differential Scanning Calorimetry (DSC) Measurements. Thermal transitions in the samples were investigated with a Perkin-EImer model DSC-7. The weight of each sample was 9-12 $\mathrm{mg}$, and a heating rate of $15 \mathrm{~K} / \mathrm{min}$ was employed. The $T_{g}$ of the demixed samples was measured after anneal ing at $124{ }^{\circ} \mathrm{C}$ under nitrogen for $20 \mathrm{~min}, 2 \mathrm{~h}, 4.5 \mathrm{~h}, 6 \mathrm{~h}, 8 \mathrm{~h}, 12 \mathrm{~h}$, $16 \mathrm{~h}$, and $24 \mathrm{~h}$.

Solid State NMR Measurements. The blend samples were placed in ceramic magi c-angle-spinning NMR cylinders for further measurements. All the spectra were taken on a Bruker MSL 300 spectrometer $\left({ }^{13} \mathrm{C}\right.$ at $\left.75.74 \mathrm{MHz}\right)$ equipped with a VT 1000 temperature controller. We performed the following three types of experiments:

${ }^{1} \mathbf{H}$ Wideline Spectra. In one of the simplest NMR experiments, the ${ }^{1} \mathrm{H}$ wideline spectrum is obtained by Fourier transformation of the ${ }^{1} \mathrm{H}$ NMR signal after a $90^{\circ}$ pulse on the protons. As a result of ${ }^{1} \mathrm{H}-{ }^{1} \mathrm{H}$ dipolar couplings, immobile segments exhibit line widths of $\sim 50 \mathrm{kHz}$. Mobile segments show motionally narrowed lines. In the limit of very fast and isotropic mobility, signals with widths of $10 \mathrm{~Hz}$ or less are observed, as is known from solution NMR. In our system, the signal of the mobile components (mostly PVME) is motionally narrowed by factors of $10-100$ and dominates the spectrum because it is narrow and intense. Thus, the ${ }^{1} \mathrm{H}$ spectrum provides information on the mobility in the PVME-rich phase. We performed the experiment under magic-angle spinning at $1 \mathrm{kHz}$ to remove line broadening due to suscepti bility effects, field inhomogeneity, etc. In the data analysis, line widths for samples of different compositions and thermal histories were compared.

$\mathbf{T}_{\mathbf{1}_{\rho}}$ Measurements. The ${ }^{1 \mathrm{H}}$ spin-lattice relaxation times in the rotating frame, ${ }^{15} T_{1 \rho}$, were measured for both blend components. $T_{1 \rho}$ is the time constant of the intensity decay of the corresponding ${ }^{13} \mathrm{C}$ signals observed in the MAS spectrum after ${ }^{1} \mathrm{H}-{ }^{13} \mathrm{C}$ cross-polarization. The ${ }^{1} \mathrm{H}$ spin lock time, $\tau$, was varied from 0 to $20 \mathrm{~ms}$, with a locking field of $\gamma \mathrm{B}_{1}=2 \pi$ (50 $\mathrm{kHz}$ ). $\mathrm{T}_{1 \rho}$ relaxation times are sensitive to the spectral densities of segmental motions at $\gamma \mathrm{B}_{1}$, exhibiting a minimum for a correlation time $\tau_{\mathrm{c}} \sim 1 / \gamma \mathrm{B}_{1}$. Due to the very different mobilities of pure PVME and PS, their $T_{1 \rho}$ values near $300 \mathrm{~K}$ are drastically different ( 0.35 and $8 \mathrm{~ms}$, respectively). In a system mixed on a $5 \mathrm{~nm}$ level, ${ }^{1} \mathrm{H}$ spin diffusion results in an averaging of the relaxation rates (inverse relaxation times), which makes it possible to estimate phase composition. 

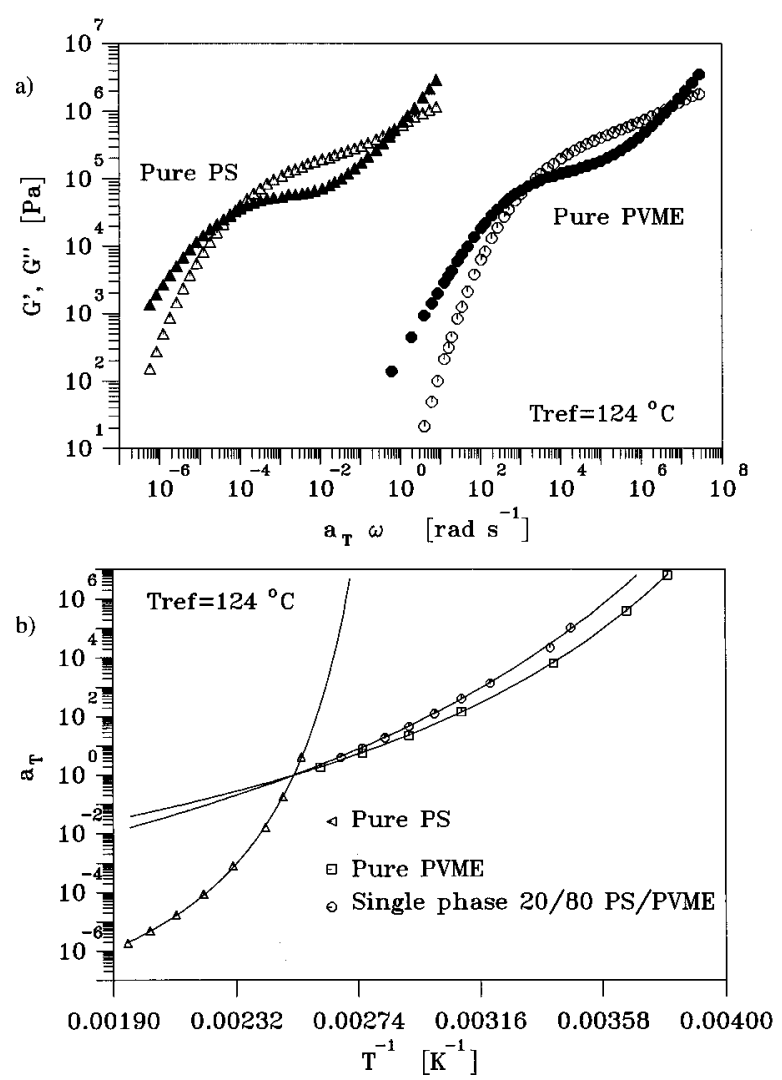

Figure 1. (a) Master curves of storage modulus ( $\left.G^{\prime}\right)$ and loss modulus ( $\left.G^{\prime \prime}\right)$ for pure PS and pure PVME at a reference temperature of $124^{\circ} \mathrm{C}$. (b) Horizontal shift factors for the pure components and the single-phase 20/80 PS/PVME blend at a reference temperature of $124^{\circ} \mathrm{C}$.

WISE-2D and Spin Diffusion Experiments. The twodimensional wide-line separation (2D WISE) NMR experiment ${ }^{16}$ makes it possible to determine the mobilities of $\mathrm{PS}$ and PVME separately and characterize the phase composition on a length scale of $1-30 \mathrm{~nm}$. The wide-line spectra of the protons in the environment of PS and PVME are observed along the $\omega_{1}$ dimension, at the PS and PVME ${ }^{13} \mathrm{C}$ chemicalshift positions, respectively, which are separated along the $\omega_{2}$ chemical shift axis. By introducing a mixing time flanked by two additional $90^{\circ}$ pulses, ${ }^{1} \mathrm{H}$ spin diffusion can be introduced before the cross-polarization. ${ }^{16}$ Thus, the diameter of the environment of the ${ }^{13} \mathrm{C}$ sites giving rise to the associated ${ }^{1} \mathrm{H}$ spectra in the 2D WISE experiment can be varied from 1 to $\sim 30 \mathrm{~nm}$. The composition of the PS-rich regions and their environment can be determined indirectly through the mobility information provided by the width and line shape of the ${ }^{1} \mathrm{H}$ wide-line spectrum: If PVME is significantly mixed with PS on the 30-nm scale, the corresponding sharp PVME peak should be observed in the ${ }^{1} \mathrm{H}$ line shape at the ${ }^{13} \mathrm{C}$ chemicalshift position of PS.

The spinning speed was set to $4 \mathrm{kHz}$, and three different mixing times were employed $\left(t_{m}=1 \mathrm{~ms}, t_{m}=10 \mathrm{~ms}, t_{m}=200\right.$ $\mathrm{ms})$. Twenty-four $\mathrm{t}_{1}$ increments with a dwell time of $10 \mu \mathrm{s}$ were used in the 2D experiments. Before detection, the TOSS fourpulse sequence ${ }^{17}$ was applied to suppress spinning side bands.

\section{Results}

Rheology. For reference, we show master curves for pure PS and PVME, at a reference temperature of 124 ${ }^{\circ} \mathrm{C}$ (Figure 1a). Figure $1 \mathrm{~b}$ shows the horizontal shift factor $\mathrm{a}_{\mathrm{T}}$, for the pure components and the single-phase 20/80 PS/PVME blend. The reference temperature for all of the data is $124^{\circ} \mathrm{C}$ even though measurements on pure PVME at $124{ }^{\circ} \mathrm{C}$ were not possible due to extremely low torque values. Data for the single-phase 20/80 PS/PVME blend at $124{ }^{\circ} \mathrm{C}$ could also not be
Table 1. Shift Factors at $124^{\circ} \mathrm{C}$ and WLF Parameters for Pure PVME, Pure PS and the Single-Phase 20/80 PS/ PVME Blend

\begin{tabular}{lcccc}
\hline \multicolumn{1}{c}{ components } & $\mathrm{T}_{\text {ref }}\left({ }^{\circ} \mathrm{C}\right)$ & $\mathrm{C}_{1}$ & $\mathrm{C}_{2}(\mathrm{~K})$ & $\log \alpha_{\mathrm{T}}$ at $124{ }^{\circ} \mathrm{C}$ \\
\hline PVME & 110 & 4.45 & 202.040 & -0.2884 \\
PSPVME2080 & 105 & 4.55 & 176.270 & -0.4427 \\
PS & 240 & 3.28 & 182.690 & 5.7052
\end{tabular}

obtained due to phase separation. Instead, the shift factor of pure PVME was expressed with the WLF equation

$$
\log a_{T}=\frac{-C_{1}\left(T-T_{\text {ref }}\right)}{C_{2}+\left(T-T_{\text {ref }}\right)}
$$

and extrapolated to $124^{\circ} \mathrm{C}$. The values of the WLF constants for all of our materials are presented in Table 1.

At early times (28 min from the onset of phase separation), the phase transition was accompanied by a large increase in $G^{\prime}$ and $G^{\prime \prime}$, at low frequencies. If one compares Figures 1 and $2 a$ and $b$ (where we present the dynamic moduli of the phase-separated blends after annealing at $124{ }^{\circ} \mathrm{C}$, for $28 \mathrm{~min}, 2.5 \mathrm{~h}, 14 \mathrm{~h}$, and $42 \mathrm{~h}$ ), one observes an increase of the moduli towards the values of pure PS. However, at longer times the rheological data express a softening of the material by a pronounced decrease of $G^{\prime}$ and $G^{\prime \prime}$ toward values of pure PVME. This is shown by the data of Figure 2, where the dynamic moduli of the phase-separated material are compared with the dynamic moduli of the pure PVME and the single-phase data of the 20/80 PS/ PVME blend. High-frequency $G^{\prime}, G^{\prime \prime}$ data for the phaseseparated blend superimposed on the data of the mixed $20 / 80$ blend that was shifted to $124^{\circ} \mathrm{C}$. This suggests that the high-frequency behavior was not affected by the phase separation.

After $28 \mathrm{~min}$, in the low-frequency regime $(0.1-1 \mathrm{rad} /$ $\mathrm{s})$, the dynamic moduli are very high, $\mathrm{G}^{\prime}$ is parallel to $\mathrm{G}^{\prime \prime}$, and both scale according to $\omega^{0.45}$. At longer times the dynamic moduli of the phase-separated system appeared to decrease. The slopes of $\mathrm{G}^{\prime}$ and $\mathrm{G}^{\prime \prime}$ increased with time but $\mathrm{G}^{\prime}$ and $\mathrm{G}^{\prime \prime}$ remained almost parallel at low frequencies even after $42 \mathrm{~h}$. After annealing for 2.5 $h$ at $124^{\circ} \mathrm{C}$, the low-frequency $\mathrm{G}^{\prime}$ and G" values were nearly proportional to $\omega^{0.62}$ over two decades of frequency, while, after $14 \mathrm{~h}$ at $124^{\circ} \mathrm{C}$, they were nearly proportional to $\omega^{0.80}$ for the same range of frequencies. After annealing at $124^{\circ} \mathrm{C}$ for $42 \mathrm{~h}, \mathrm{G}^{\prime}$ and G" scale with $\omega^{0.92}$ again over the same two decades of frequency.

The softening of the material is al so evident from the $\tan \delta$ data as presented in Figure 2c. If one compares the $\tan \delta$ of the phase-separated blend at different times with that of pure PS, it is interesting to observe that the minimum in the tan $\delta$ curve that can be attributed to the PS-rich phase becomes more pronounced at longer times. A reasonable explanation for this behavior is based on the fact that initially the PS-rich phaseseparated domains are uniformly distributed throughout the whole sample. However, at longer times they form a network imbedded in the PVME-rich phase. As the network breaks, the PS-rich phase becomes "more separated" from the PVME-rich phase. Thus, the minimum in tan $\delta$ that corresponds to the PS-rich phase becomes more pronounced.

Analysis of the Rheological Data. Phase transition in blends affects dynamic mechanical data mostly at low frequencies. Single-phase melts exhibit $\mathrm{G}^{\prime} \sim \omega^{2}$; 
a)
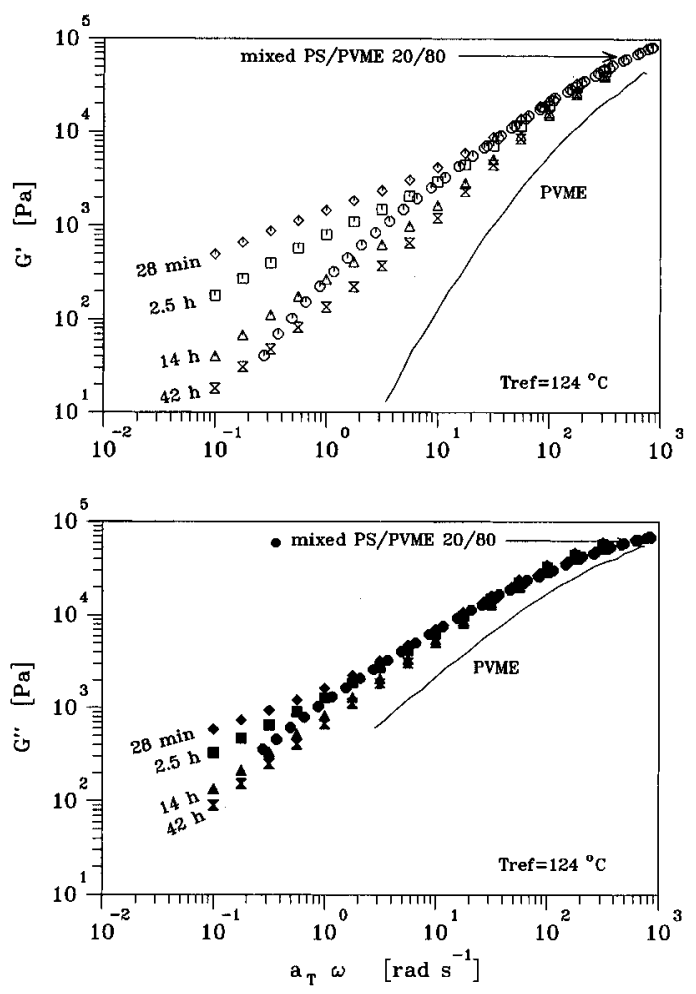

c)

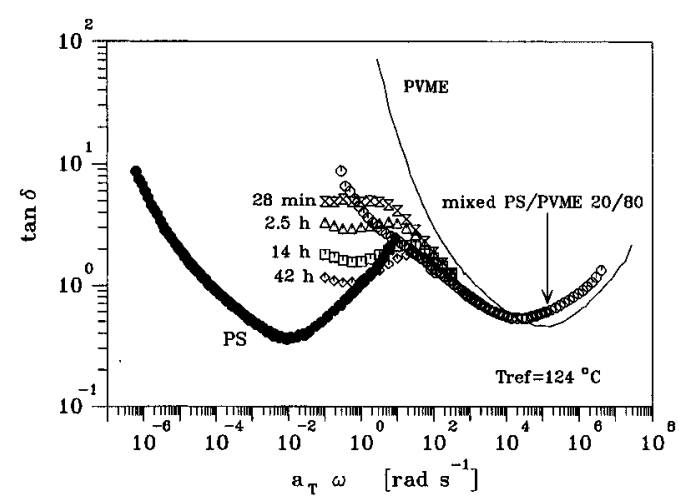

Figure 2. (a) Storage modulus of the phase-separated $20 / 80$ PS/PVME polymer blend at different times. The highfrequency data of the phase-separated system al ways superimpose on the data of the mixed blend shifted at $124^{\circ} \mathrm{C}$. The terminal zone of the loss modulus of pure PVME (at $124^{\circ} \mathrm{C}$ ) is presented as a reference (solid line). (b) Loss modulus of the phase-separated 20/80 PS/PVME polymer blend at different times. The high-frequency data of the phase-separated system always superimpose on the data of the mixed blend shifted at $124{ }^{\circ} \mathrm{C}$. The terminal zone of the loss modulus of pure PVME (at $124^{\circ} \mathrm{C}$ ) is presented as reference (solid line). (c) Evolution with time of $\tan \delta$ of the phase-separated 20/80 $\mathrm{PS} / \mathrm{PVME}$ polymer blend at $\mathrm{T}=124^{\circ} \mathrm{C}$. For reference we also present the $\tan \delta$ of purePVME, pure PS, and the single-phase 20/80 blend, all shifted at $124{ }^{\circ} \mathrm{C}$.

$\mathrm{G}^{\prime \prime} \sim \omega$ at low frequencies. Phase-separated melts show $\mathrm{G}^{\prime} \sim \mathrm{G}^{\prime \prime} \sim \omega^{\mathrm{n}} \cdot 7,18,19$

Power law relaxation ${ }^{20,21}$ expresses itself by

$$
\mathrm{G}^{\prime}=\mathrm{G}^{\prime \prime} / \tan \frac{\mathrm{n} \pi}{2}=\mathrm{S} \omega^{\mathrm{n}} \Gamma(1-\mathrm{n}) \cos \frac{\mathrm{n} \pi}{2}
$$

where $\mathrm{n}$ is the power law exponent while the phase angle $\delta$ between $\mathrm{G}^{\prime}$ and $\mathrm{G}^{\prime \prime}$ is expressed as

$$
\delta=\frac{\mathrm{n} \pi}{2}
$$

$\Gamma$ is the $\Gamma$-function.

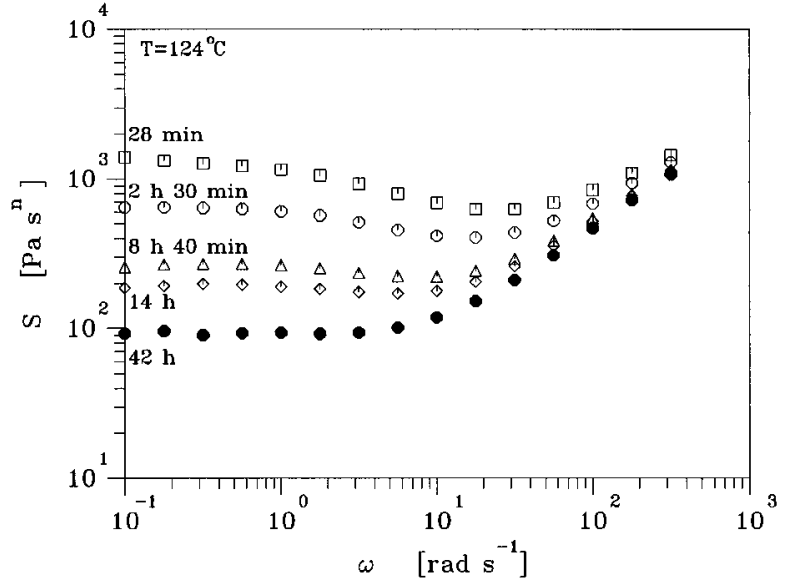

Figure 3. Evolution of the gel strength, $S$, of a phaseseparated 20/80 PS/PVME polymer blend as a function of phase-separation time.

The gel stiffness $\mathrm{S}$ is a constant in the power law region. However, we can define a frequency dependent stiffness

$$
\mathrm{S}^{*}(\omega)=\sqrt{\mathrm{S}^{\prime 2}+\mathrm{S}^{\prime \prime 2}}=\frac{\mathrm{G}^{*}(\omega)}{\omega^{\mathrm{n}} \Gamma(1-\mathrm{n})}
$$

with

$$
\begin{aligned}
\mathrm{S}^{\prime}(\omega)=\frac{\mathrm{G}^{\prime}}{\omega^{\mathrm{n}} \Gamma(1-\mathrm{n})^{\prime}}, \mathrm{S}^{\prime \prime}(\omega)= & \frac{\mathrm{G}^{\prime \prime}}{\omega^{\mathrm{n}} \Gamma(1-\mathrm{n})} ; \\
& \mathrm{n}(\omega)=\frac{2}{\pi} \tan ^{-1} \frac{\mathrm{G}^{\prime \prime}}{\mathrm{G}^{\prime}}
\end{aligned}
$$

Plots of $\mathrm{S}^{*}(\omega)$ allow observation of power law relaxation as it develops (at low frequencies for our experiments). The values of $S^{*}(\omega)$ are presented in Figure 3 and are found to be constant for more than one decade of frequency. Interestingly enough the values of $S^{*}$ vs phase-separation time (Figure 4a) can be approximated by a power law, at times longer than $1 \mathrm{~h}$. The same behavior is evident for the critical exponent $n$, which also exhibits a power law behavior vs time (Figure $4 b$ ).

The power law behavior is not a property of the transition (like in polymers at the gel point). It is a property of the phase-separated structure. The phaseseparated melt is still a liquid. We expect that the power law behavior is not continuing to zero frequency, but it will cross over to the typical liquid behavior, ' $\mathrm{G}^{\prime}$ $\sim \omega^{2}, \mathrm{G}^{\prime \prime} \sim \omega$. Our experiments could not be extended far enough to see this cross-over.

\section{Optical Microscopy}

Hoffman Modulation Microscopy. Two pictures showing the time evolution of the phase-separated morphology are presented in Figure $5 a$ and $b$. The pictures were taken using a $10 \times \mathrm{H}$ offman modulation objective. The "identity" of the phase-separated domains can be detected if one compares the photographs of a phase-separated sample with those of a reference sample. For this purpose we cast polystyrene microspheres from a nonsolvent onto a microscope slide. Pictures of these microspheres were taken using a 30x $\mathrm{H}$ offman modulation objective. Under the same conditions we took pictures of a phase-separated blend that was held at $124{ }^{\circ} \mathrm{C}$ for $27 \mathrm{~h}$. These pictures are shown in Figure 5c. Due to H offman modulation contrast ${ }^{13}$ the bottom part of the polystyrene microspheres appears 


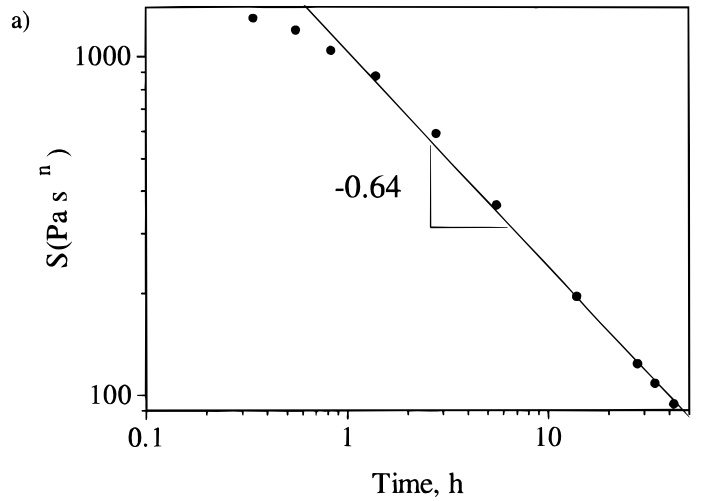

b)

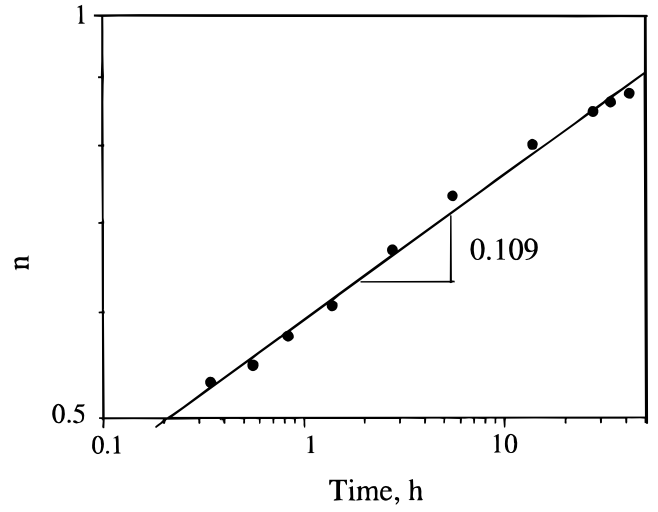

Figure 4. (a) Power law behavior of $S$ vs time. The slope of the fit gives an exponent equal to -0.64 . (b) Power law behavior of the critical exponent $n$ of eq 5 vs phase-separation time. The slope of the fit gives an exponent equal to 0.109.

black while the top part appears bright. This is due to the difference between the indexes of refraction of the PS spheres $\left(n_{D}=1.592\right)$ and the air $\left(n_{D}=1\right)$, which forms the "matrix" phase on the microscope slide. The same contrast effects can be seen in Figure $5 c$ for the phase-separated PS/PVME blend, where the high index of refraction phase (PS-rich) forms the minority (matrix) phase while the low index of refraction phase (PVMErich) forms the dispersed phase. (PVME has $n_{D}=$ 1.467.)

Conventional Optical Microscopy. A series of pictures showing the time evolution of the phaseseparated morphology is presented in Figure 6. These were taken with the $50 \times$ objective lens. In Figure 6a one can see the late stages of spinodal decomposition. After $2.5 \mathrm{~h}$ one of the initially cocontinuous phases forms a continuous matrix phase (Figure 6b). At longer times (Figure $6 \mathrm{c}$ and $\mathrm{d}$ ) the ratio of the volume fractions of the matrix and the dispersed phase changes dramatically. The major part of these morphological changes seems to be complete after $14-15 \mathrm{~h}$.

During the evolution of the phase-separated morphology we performed the Becke test 22 in order to identify which of the phases forms the continuous matrix phase. The Becke test showed that at early times (up to $2.5 \mathrm{~h}$ ) the lower refractive index phase (PVME-rich) formed the minority (dispersed) phase of the system, since the Becke hal o was moving toward the matrix phase (higher refractive index phase) when we raised the position of focus. At longer times (i.e. after $14 \mathrm{~h}$ ) the Becke line still moves toward the matrix phase (which is now the minority phase of the system), when we raise the position of focus. These tests confirm the results from the Hoffman modulation contrast (Figure $5 a$ and b).

At this point we have to mention that we considered the dimensionality effect. It was tested whether the

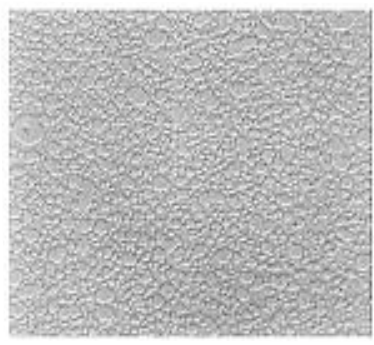

a) $6 \mathrm{~h} 15 \mathrm{~min}$

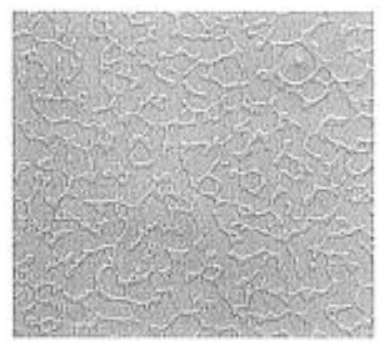

b) $16 \mathrm{~h} 15 \mathrm{~min}$

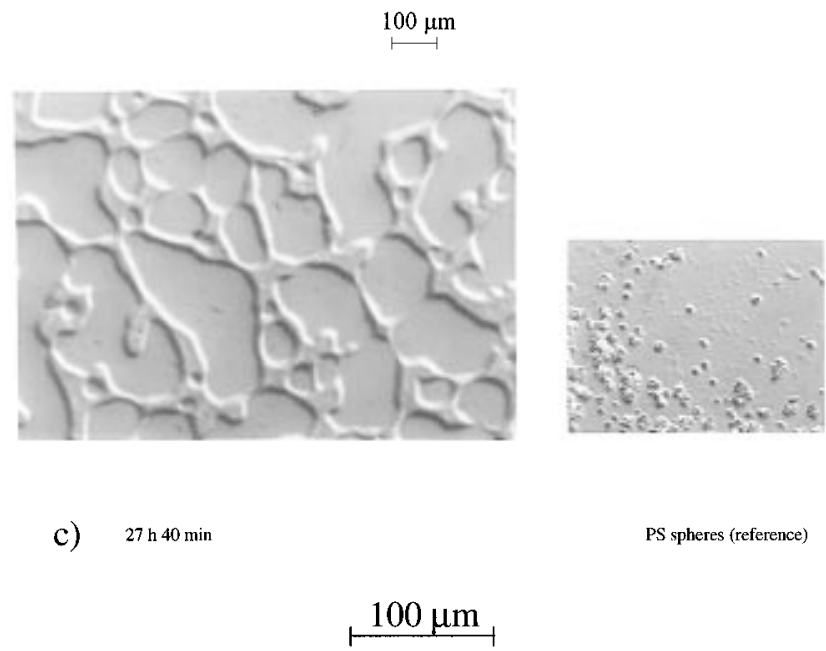

Figure 5. (a) Phase-separated morphology of a 20/80 PS/ PVME polymer blend after $6 \mathrm{~h}$ and $15 \mathrm{~min}$ at $124^{\circ} \mathrm{C}$, as seen through a 10x Hoffman modulation lens. The matrix phase is PS-rich, as demonstrated by the micrograph in part c. (b) Phase-separated morphology of a 20/80 PS/PVME polymer blend after $16 \mathrm{~h}$ and $15 \mathrm{~min}$ at $124^{\circ} \mathrm{C}$, as seen through a $10 \times$ Hoffman modulation lens. (c) Phase-separated 20/80 PS/PVME blend that was held at $124{ }^{\circ} \mathrm{C}$ for $27 \mathrm{~h}$, compared with polystyrene microspheres cast on a microscope slide from a nonsolvent. The pictures were taken through a $30 \times \mathrm{H}$ offman modulation lens.

optical microscopy results of our thin films represent the morphology of the phase-separated bulk sample or if the presence of the surface affects the morphology. For this purpose, we cut $25 \mu \mathrm{m}$ thick slices from the bulk samples and performed optical microscopy studies under the same conditions as in the case of the thin films. In both cases, we observed similarity regarding the shape and the size of the phase-separated domains. Finally, in order to explain the formation of a distribution of droplets from the initially interpenetrating phases and the role and value of the interfacial tension, we applied the breaking thread method. ${ }^{23}$ This work will be described in detail, along with our modeling effort, in a future publication.

Digital Image Analysis of the Micrographs. Digital image analysis for the study of phase separation of polymer blends was first used by Tanaka, Hayashi, and $\mathrm{Nishi},{ }^{24,25}$ who analyzed images of phase-separated blends obtained by a phase contrast mi croscope. In our case, pictures taken using conventional optical microscopy were digitized and processed by digital image analysis (DIA). A two-color image was obtained by painting one phase black and the other white. A typical sequence of black and white pictures is presented in Figure 7. Subsequently each domain was analyzed and the perimeter length and the area were calculated. The number of domains decreases approximately inversely with time, $\mathrm{N} \sim \mathrm{t}^{-1}$ (Figure 8), while the mean periphery of the domains which scales linearly with the radius for 


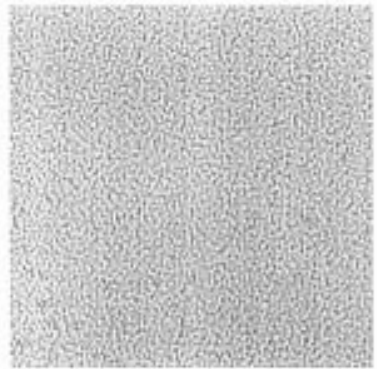

a) $28 \mathrm{~min}$
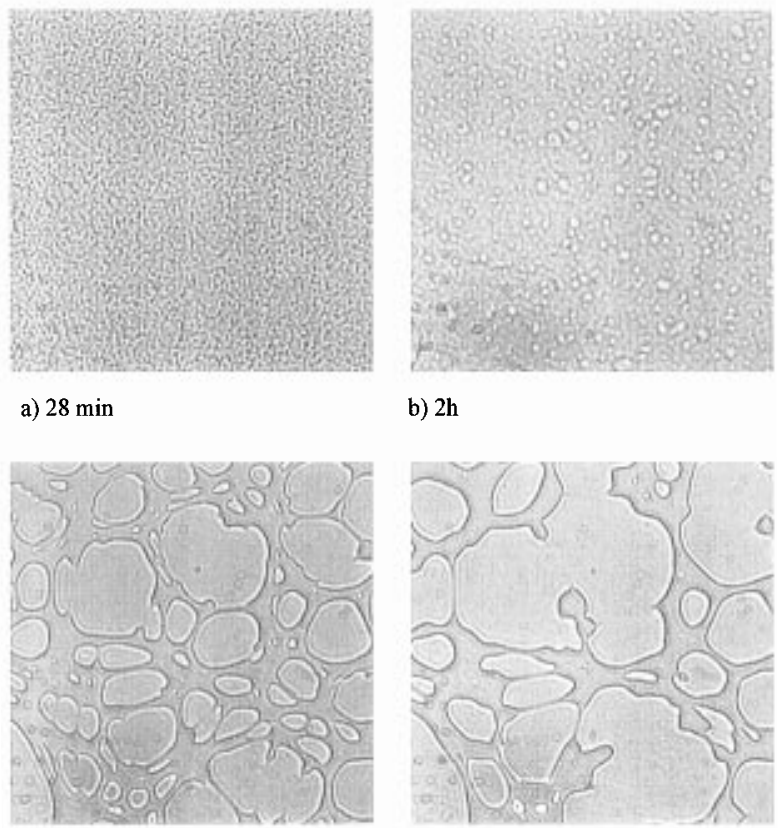

b) $2 \mathrm{~h}$

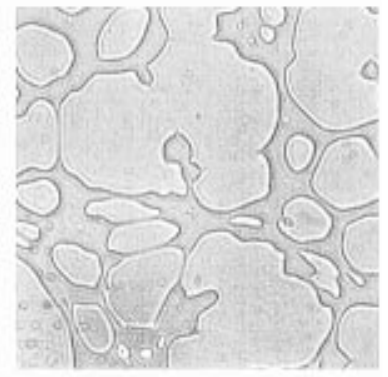

d) $14 \mathrm{~h}$

$100 \mu \mathrm{m}$

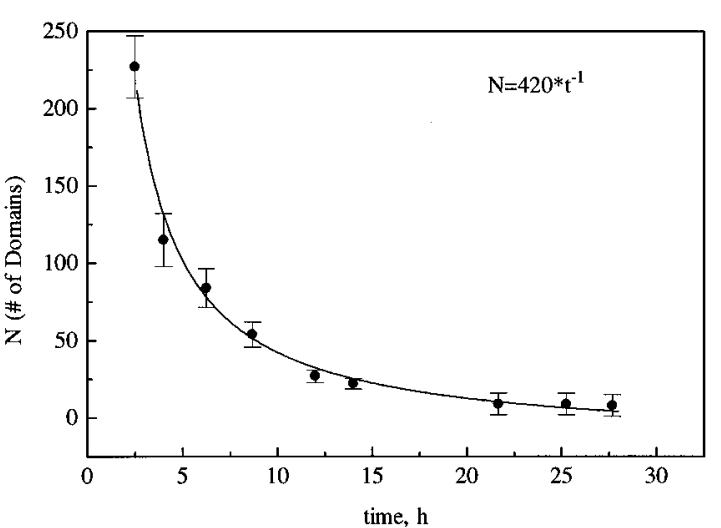

Figure 8. Time dependence of the number of phase-separated domains. The equation describes the fit through the data points.

a)

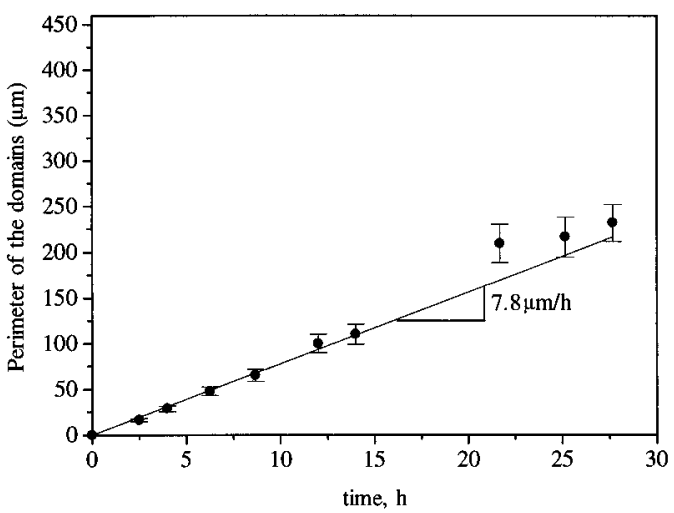

Figure 6. Phase-separated morphology of a 20/80 PS/PVME blend at $124{ }^{\circ} \mathrm{C}$, as seen through a $50 \times$ conventional microscopy lens: (a) after 28 min from the onset; (b) after $2 \mathrm{~h}$ at 124 ${ }^{\circ} \mathrm{C}$; (c) after $8 \mathrm{~h}$ and $40 \mathrm{~min}$ at $124{ }^{\circ} \mathrm{C}$; (d) after $14 \mathrm{~h}$ at $124{ }^{\circ} \mathrm{C}$.

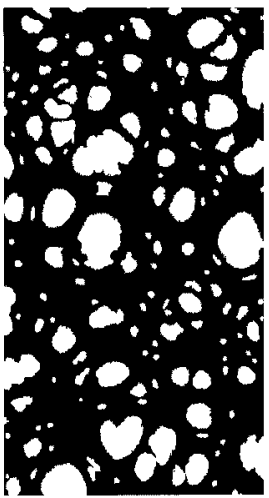

4 hours

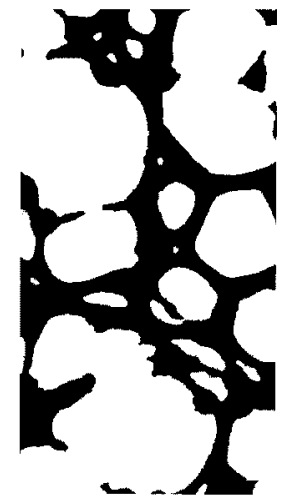

12 hours

$$
100 \mu \mathrm{m}
$$

Figure 7. Evolution of the phase-separated morphology through a sequence of black and white pictures. The pictures were obtained after processing the original images taken with a 50x conventional microscopy lens with digital image analysis software.

circular domains changes linearly with time, as pre sented in Figure 9a. In order to show the influence of the size of the domains, we present in Figure 9b the area-weighted periphery of the domains that is more sensitive to bigger sizes. This area-weighted periphery of the domains increases almost linearly and reaches a plateau after $14 \mathrm{~h}$.

Electron Microscopy. For all the images presented in this section, the dark regions correspond to the PSrich phase, while the bright regions correspond to the PVME-rich phase. Figure 10a and b (corresponding to $20 \mathrm{~min}$ from the onset of phase separation) shows highly interconnected uniform size distribution domains in agreement with the spinodal decomposition character of phase separation of this particular blend system. After $2 \mathrm{~h}$ from the onset of phase separation, we observe

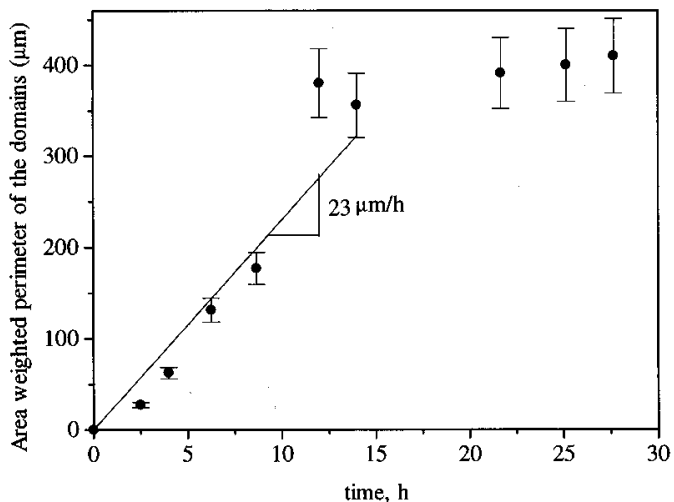

Figure 9. (a) Linear growth of the phase-separated domains. The slope of the linear fit gives the velocity of growth in $\mu \mathrm{m} /$ h. (b) Time evolution of the area-weighted periphery of the domains. The slope of the linear fit gives the velocity of growth in $\mu \mathrm{m} / \mathrm{h}$. The values in parts $\mathrm{a}$ and $\mathrm{b}$ are different due to $\mathrm{a}$ wide distribution of domain sizes.

larger PVME-rich domains with diameters that vary approximately between 0.1 and $4 \mu \mathrm{m}$. In the corresponding optical micrographs domains with diameters up to $3 \mu \mathrm{m}$ are observed. The shape of the domains varies from spherical to ellipsoidal, while coalesced dispersed domains also exist. The size and the shape of the domains vary depending on the sample area selected, as shown in Figure 10c-e, where different images correspond to different sample areas. I nterestingly enough, in all cases only thin sections of the PSrich "matrix" phase are observable, while a very broad size distribution of the PVME-rich droplets is detected. The subsequent coalescence of the small PVME-rich domains into bigger spherical and ellipsoidal domains as well as the formation of a PS-rich network morphology is presented in Figure 10f-h taken for a sample 

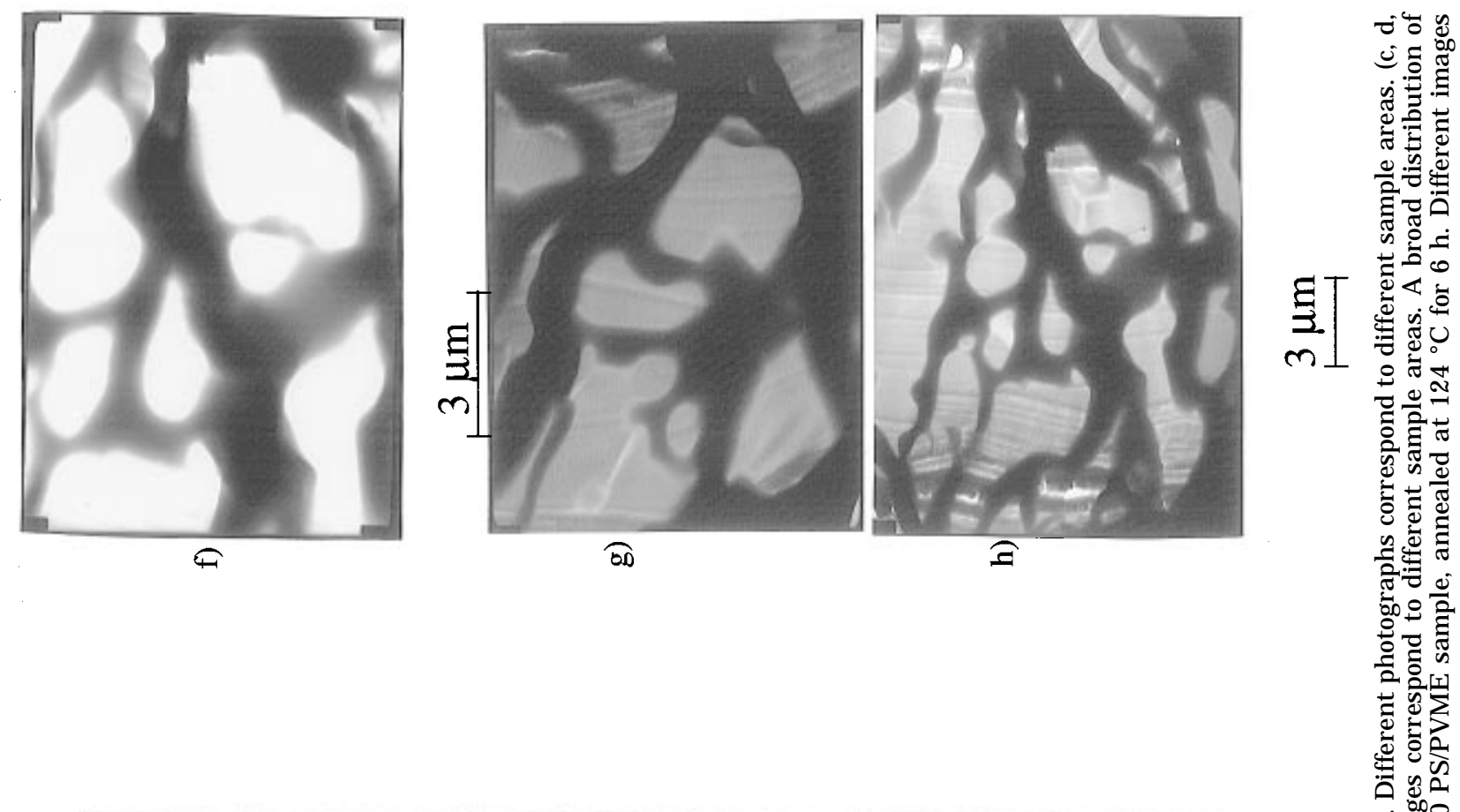

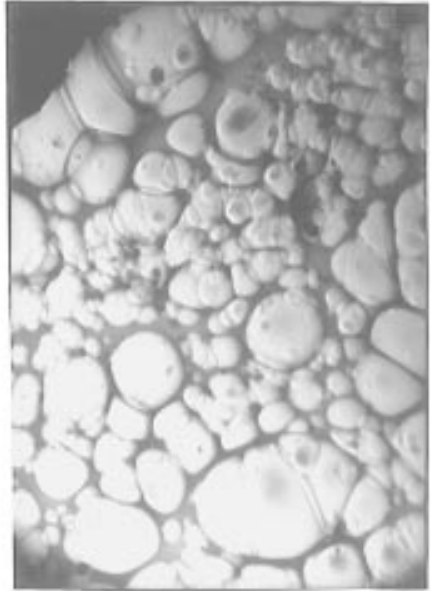

o

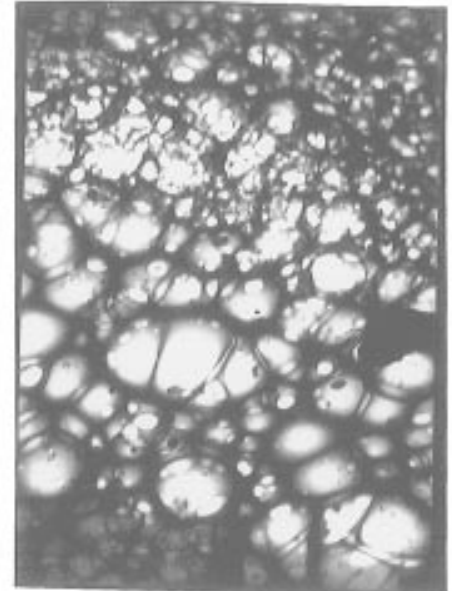

$\delta$

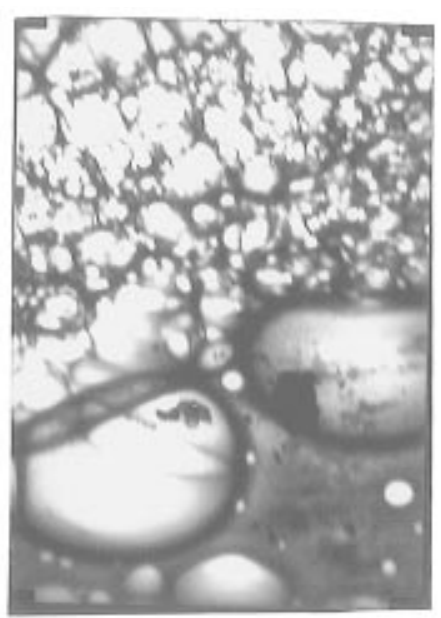

(ิ)

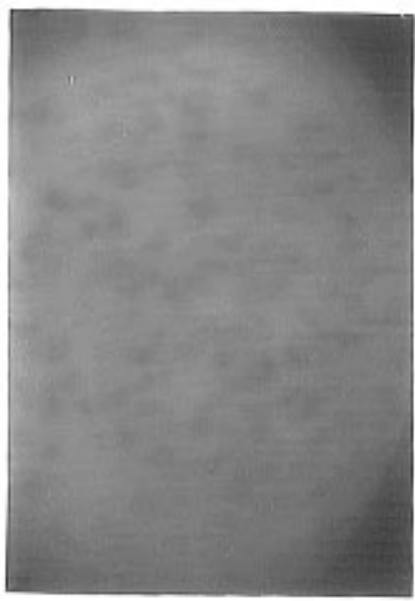

ส

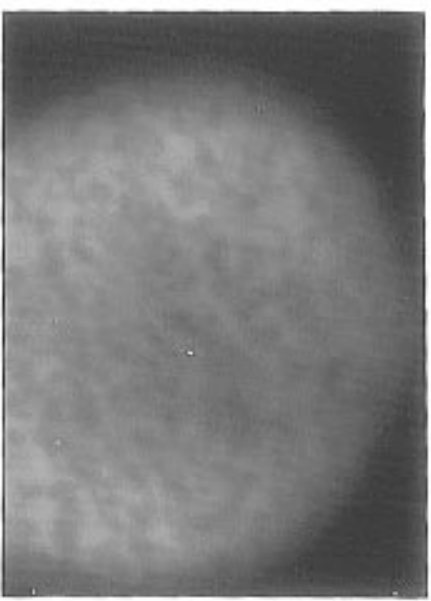

0

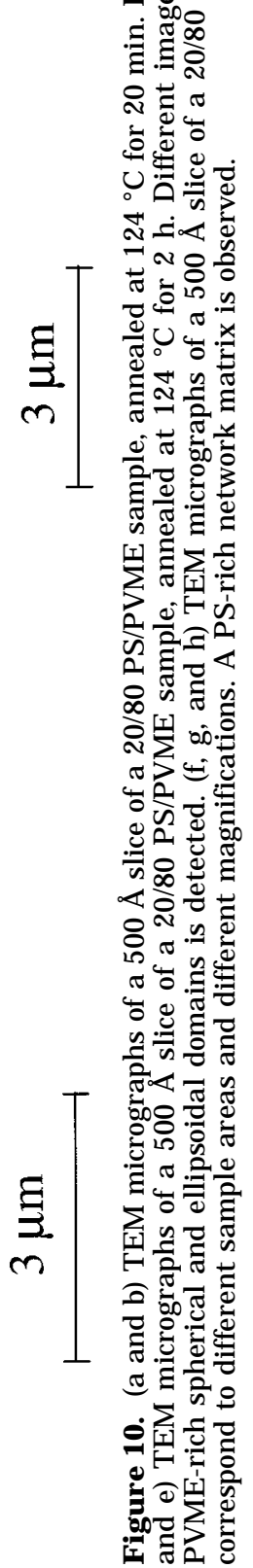




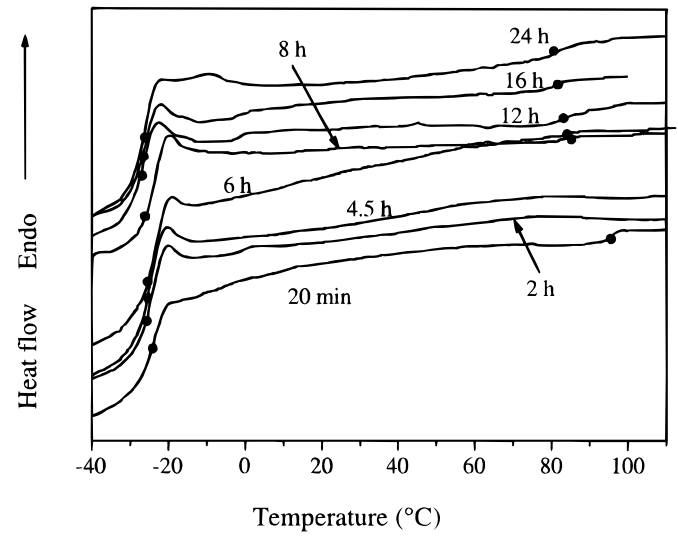

Figure 11. DSC curves of the phase-separated 20/80 PS/ PVME polymer blend after annealing at $124{ }^{\circ} \mathrm{C}$ at different times.

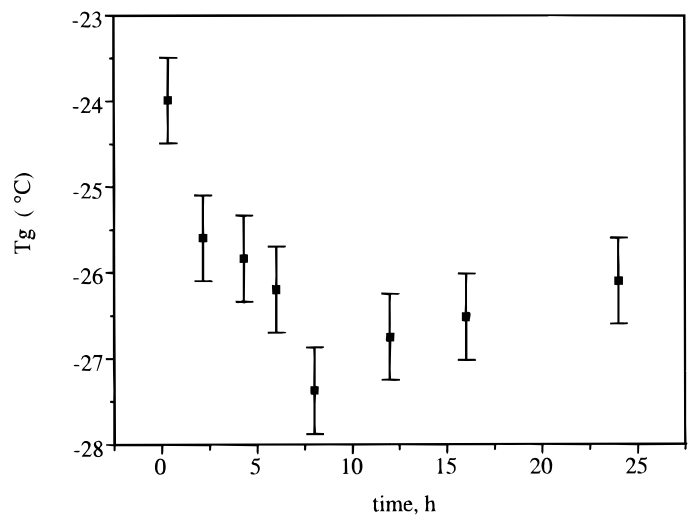

Figure 12. Evolution with time of the $T_{g}$ of the PVME-rich phase.

annealed at $124{ }^{\circ} \mathrm{C}$ for $6 \mathrm{~h}$. Thicker sections of the PSrich network originate from the coalescence of the PVME-rich droplets.

\section{DSC Measurements of the Glass Transition Temperature}

Typical thermographs of the phase-separated blends at different times are presented in Figure 11. The $\mathrm{T}_{\mathrm{g}}$ of the PS-rich phase drops from $95{ }^{\circ} \mathrm{C}$ (20 min after phase separation) to $80^{\circ} \mathrm{C}$ (after $24 \mathrm{~h}$ ). No Tg of the PS-rich phase was detectable when the sample was annealed for 2 and $4.5 \mathrm{~h}$; the $\mathrm{T}_{\mathrm{g}}$ of the PS-rich phase "reappears" after $6 \mathrm{~h}$ and becomes distinct again after $12 \mathrm{~h}$ but still cannot be clearly detected. The $\mathrm{T}_{\mathrm{g}}$ of the PVME-rich phase through the whole annealing period ranges from -25 to $-27.5^{\circ} \mathrm{C}$. The variation of $\mathrm{T}_{\mathrm{g}}$ with time for the PVME-rich phase is presented in Figure 12.

Analysis of the DSC Data. The average concentration of the phase-separated domains was estimated from the $T_{g}$ of the miscible blends in the one-phase region. The measured $\mathrm{T}_{\mathrm{g}}$ of the blends in the one-phase region is in good agreement with the data presented in ref 5. The $T_{g}$ of the one-phase blends can be appoximated by the empirical Kwei equation ${ }^{26}$ used to describe the $T_{g}$ of several types of polymer blends:

$$
T_{g}=\frac{w_{1} T_{g 1}+k w_{2} T_{g 2}}{w_{1}+k w_{2}}+q w_{1} w_{2}
$$

Here, $w_{i}$ and $T_{g i}$ are the weight fraction and the $T_{g}$ of the pure components, respectively, and the parameters

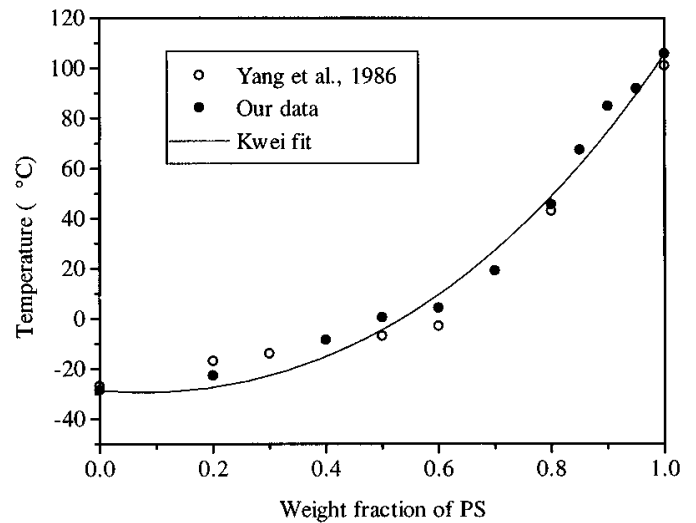

Figure 13. Glass transition temperatures of mixed PS/PVME blends for various compositions. The line through the data represents the Kwei fit described by eq 6 . Our data are compared with data from ref 5.

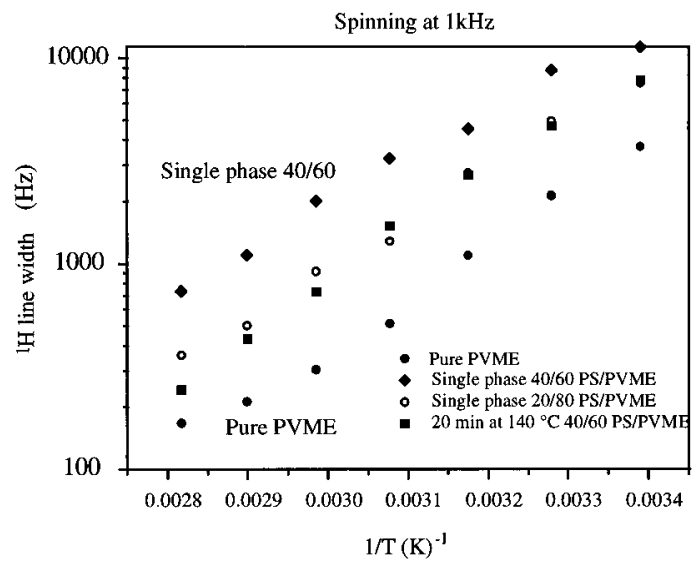

Figure 14. ${ }^{1} \mathrm{H}$ line widths for pure PVME and single-phase 20/80 and 40/60 PS/PVME blends. For comparison, we present the data that correspond to a phase-separated 40/60 PS/PVME blend that was anneal ed at $140{ }^{\circ} \mathrm{C}$ for $20 \mathrm{~min}$. The data were recorded at a spinning rate of $1 \mathrm{kHz}$.

$\mathrm{k}$ and $\mathrm{q}$ are the $\mathrm{K}$ wei parameters, which are adjusted to fit the experimental data.

By applying such a $\mathrm{K}$ wei fit (with $\mathrm{k}=95$ and $\mathrm{q}=1.8$ $K$ ) to the $T_{g}$ data of the miscible blends (see Figure 13) and comparing the $T_{\mathrm{g}}$ values at different concentrations, one finds that the concentration of the PVME-rich phase is almost $90-95 \%$ pure PVME. At this point we have to mention the difficulty that we encounter when we try to extract the composition of the two phases based on the DSC data. At high PVME content the DSC curve shows a pronounced $\mathrm{T}_{\mathrm{g}}$ transition but the composition curve is flat and insensitive to the amount of PS that it contains. At low PVME content the $\mathrm{T}_{\mathrm{g}}$ vs composition curve is sharp but the DSC is insensitive to the glass transition. Because of this, the error in finding the PS content is large for either component. This forced us to perform the more elaborate NMR experiments.

\section{NMR Results}

1H Line Widths. Our results on pure PVME and single-phase 20/80 and 40/60 PS/PVME samples (F igure 14) Show that addition of PS reduces the mobility in the PVME-rich phase. F or the case of the 40/60 PS/PVME that is kept at $140{ }^{\circ} \mathrm{C}$ for $20 \mathrm{~min}, 2 \mathrm{~h}, 14 \mathrm{~h}$, and $24 \mathrm{~h}$ (Figure 15) an increase of the mobility of PVME is observed after 20 min from the onset of phase separation. However, no further increase of the mobility is evident for the data that correspond to 2, 14, and $24 \mathrm{~h}$. 


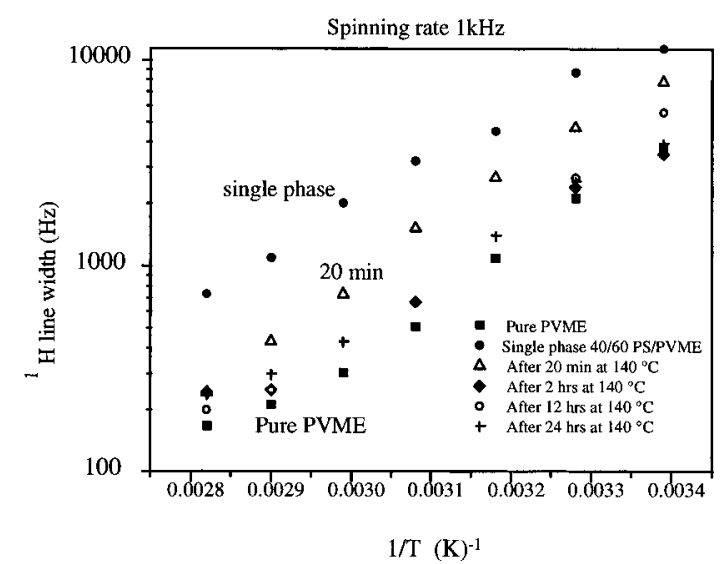

Figure 15. ${ }^{1} \mathrm{H}$ line widths for pure PVME, single-phase 40/ $60 \mathrm{PS} / \mathrm{PVME}$, and demixed 40/60 PS/PVME that was annealed at $140{ }^{\circ} \mathrm{C}$ for different times. The data were taken at a spinning rate of $1 \mathrm{kHz}$.

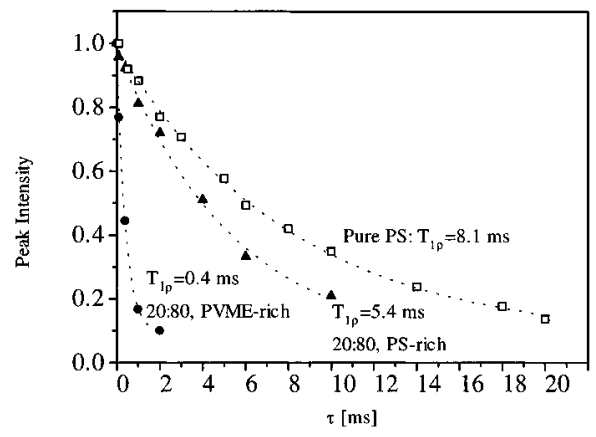

Figure 16. ${ }^{1} \mathrm{H} \mathrm{T}_{1 \rho}$ data $\left({ }^{13} \mathrm{C}\right.$-detected) of the PS-rich and the PVME-rich phases of a 20/80 PS/PVME blend that was annealed at $124{ }^{\circ} \mathrm{C}$ for $2 \mathrm{~h}$. The $T_{1_{\rho}}$ data of pure PS are also presented for comparison. The fits shown are single exponentials. All the data were taken at room temperature.

Also, there is almost no difference between the mobility in the PVME-rich phase for the three later times and that of pure PVME. The data for the $40 / 60$ blend after $20 \mathrm{~min}$ of phase separation at $140{ }^{\circ} \mathrm{C}$ and for the singlephase $20 / 80$ blend nearly coincide. This indicates that the composition of the PVME-rich phase in the 40/60 blend after $20 \mathrm{~min}$ is approximately 20/80 PS/PVME.

$\mathbf{T}_{1 \rho}$ Relaxation Times. Proton $\mathrm{T}_{1 \rho}$ relaxation curves measured at $25{ }^{\circ} \mathrm{C}$ are presented in Figure 16. The decay of the ${ }^{13} \mathrm{C}$ intensity of pure PS is shown as a function of the proton spin lock time, $\tau$, together with the ${ }^{13} \mathrm{C}$ intensity of the PS-rich and the PVME-rich phases of a 20/80 PS/PVME sample that was annealed at $124{ }^{\circ} \mathrm{C}$ for $2 \mathrm{~h}$. All three curves show simple exponential decays. The similarity of the $T_{1 \rho}$ relaxation time for the PS-rich phase and pure PS data shows that the PS-rich phase is indeed PS-rich even though the sample overall contains predominantly PVME. On the other hand, the $T_{1 \rho}$ value for the PS-rich phase is somewhat reduced compared to the value of pure PS. This shows that the PS-rich phase does contain some PVME. Using a calibration curve from the literature, ${ }^{27}$ we can estimate the concentration of the PS-rich phase to be $60 \%-70 \%$ PS. The single-exponential shape of the $\mathrm{T}_{1 \rho}$ curves indicates that the composition of the two phases is quite homogeneous. Also, it shows that the $\mathrm{T}_{1 \rho}$ relaxation is not affected by spin diffusion between different domains, indicating domain sizes larger than $5 \mathrm{~nm}$. Complementary information can be obtained through the WISE spectra, which are less affected by unknown mobility changes and domain sizes.

WISE and Spin Diffusion Results. Figure 17

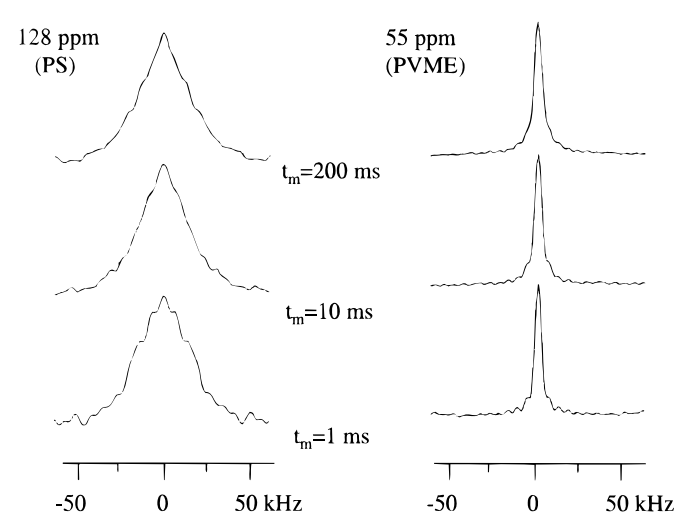

Figure 17. Series of proton wide-line spectra that correspond to PS-rich and PVME-rich phases of a 20/80 PS/PVME blend that was annealed at $124{ }^{\circ} \mathrm{C}$ for $2 \mathrm{~h}$, obtained as slices from the 2D WISE spectra. The data for three different mixing times are presented. The spinning rate was $4 \mathrm{kHz}$, and TOSS was applied before detection.

presents a series of slices that correspond to the ${ }^{1} \mathrm{H}$ wide line spectra of PS-rich and PVME-rich phases of a 20/ $80 \mathrm{PS} / \mathrm{PVME}$ blend that was annealed at $124{ }^{\circ} \mathrm{C}$ for 2 $\mathrm{h}$. The slices were taken at the most intense PS and PVME ${ }^{13} \mathrm{C}$ resonances, respectively, from $2 \mathrm{D}$ WISE spectra which were acquired with mixing times of 1,10 , and $200 \mathrm{~ms}$. In all cases, PVME exhibits narrow cross sections (high mobility) and there is no evidence of a significant background of rigid PS. This confirms that the PVME-rich phase contains predominantly PVME. On the other hand, the PS-rich phase exhibits broad cross sections (more immobile segments, as expected for regions with high polystyrene content). This is true even for the longest mixing time of $200 \mathrm{~ms}$, where spin diffusion occurs over distances of $\sim\left(4 / \pi\left(0.8 \mathrm{~nm}^{2} / \mathrm{ms}\right)(200\right.$ $\mathrm{ms}))^{1 / 2}=15 \mathrm{~nm}$. Thus, the ${ }^{1} \mathrm{H}$ line shape observed at the PS frequency is that of a region of $\sim 15 \mathrm{~nm}$ radius (30 nm diameter) around the PS segment observed. No narrow PVME peak is observed, proving that the PSrich phase neither contains nor is close to a large amount of highly mobile PVME. The somewhat narrower peak on top of the PS "bell-shaped" curve at long mixing times indicates only a $40 \pm 10 \%$ fraction of PVME of reduced mobility in the PS-rich phase. This $60 \pm 10 \%$ PS concentration in certain regions of a sample with an overall PS fraction of only $20 \%$ is remarkable. It also implies that the further concentration change for the PS-rich phase can be only relatively minor (from $60 \%$ to $100 \%$ at most). It cannot explain the drastic changes of rheol ogical properties and optical micrographs observed for longer phase-separation times.

In addition to the composition information, the WISE spectra with spin diffusion also give valuable lower limits to the domain sizes. As discussed, if the PS were within $15 \mathrm{~nm}$ from highly mobile PVME, a corresponding narrow peak would appear prominently in the center of the PS cross section for the $200 \mathrm{~ms}$ mixing time. Such a peak was indeed observed in a homogeneous PVME blend and in block copolymers. ${ }^{16}$ That this peak is not observed in our phase-separating polymer blend proves that the domain diameters are larger than $30 \mathrm{~nm}$.

\section{Discussion}

The initial stages of phase separation of the 20/80 PS/ PVME polymer blend, at $124^{\circ} \mathrm{C}$, are accompanied by an increase in the shear moduli $G^{\prime}$ and $G^{\prime \prime}$ at low frequencies, resulting in a slope of 0.45 at low frequencies, $28 \mathrm{~min}$ from the onset of phase separation. 
However, at longer times a definite decrease is observed. This decrease can be attributed to the loss of interconnectivity of the phase-separated domains, which is a result of the breakup of the PS-rich phase network and the coalescence of the PVME-rich phase droplets. The compositional changes suggested by the optical micrographs al one do not occur. However, NMR and TEM show the existence of microdomains of the PSrich and PVME-rich phases at intermediate times. The time scales for the morphological and rheological changes are in good agreement. It seems that most of the changes occur within the first $14 \mathrm{~h}$ from the onset of phase separation. This result is supported by Figure 9b, which shows that there is a certain size limit (on the order of $350 \mu \mathrm{m}$ ) that affects the rheological observations. At this point, the interconnectivity of the PSrich matrix phase almost breaks. The power law behavior of the dynamic moduli as a function of frequency suggests that the entire sample has properties characteristic of an elastic network. The power law behavior of $\mathrm{S}$ and $\mathrm{n}$ (Figure 5) as a function of phaseseparation time is also characteristic of gel systems which exhibit such a network "superstructure".

The behavior of the dynamical mechanical material functions in the early stages of phase separation resemble the results of ref 18, where a power law behavior is reported, but with a slope of 0.58 , for a phaseseparated 10/90 PS/PVME blend which was heated up to $173{ }^{\circ} \mathrm{C}$. The rheological behavior of the phaseseparated 20/80 PS/PVME blend in this time period is similar to the rheological behavior for an immiscible 70/ 30 PS/PMMA blend, ${ }^{28}$ where PS forms the matrix phase and PMMA the dispersed phase. The elevation in the low-frequency region was attributed to the higher storage and loss modulus of pure PMMA, which at the reference temperature of $170{ }^{\circ} \mathrm{C}$ was closer to the $T_{g}$ of PMMA than to the $T_{g}$ of PS. In agreement with ref 7 and the scaling analysis of Ajji and Choplin, ${ }^{29} \mathrm{G}^{\prime}$ was more sensitive to phase separation than $G^{\prime \prime}$. The effects of the morphological changes were also more pronounced for $\mathrm{G}^{\prime}$, which decreased more dramatically than G".

The 20/80 PS/PVME blend phase separates initially following the spinodal decomposition mechanism. $6,9,10$ This is indicated by the spinodal morphology seen in Figure 10a and the TEM micrograph that corresponds to $20 \mathrm{~min}$ from the onset of phase separation. However, the coarsening of the phase-separated domains persists even after $27 \mathrm{~h}$, resulting in further rheological changes, as seen in Figure 9. Such a linear growth is predicted by Siggia, ${ }^{30}$ who showed that in the late stages of phase separation one observes a crossover in the growth rate between $t^{1 / 3}$ and $t^{1}$. This model was developed to describe the late stages of spinodal decomposition of low molecular weight materials. When the minority phase is continuous, after a quench at the critical conditions, the motion of interfaces (responsible for the coal escence of droplets) is driven by the interfacial tension, $\sigma$, leading to a linear growth of the droplets according to

$$
\mathrm{r} \approx \frac{0.1 \sigma \Delta \rho_{\mathrm{t}}}{\eta}
$$

where $r$ is the radius of the droplets and $\eta$ is the zeroshear viscosity. This mechanism predicts that $\mathrm{N} \approx \mathrm{t}^{-1}$, which is also found in our data (Figure 12). The transition from the diffusive coarsening rate (which dominates in the early stages of phase separation and has a growth rate proportional to $t^{1 / 3}$ ) to the surface- tension-controlled rate (where the growth rate is proportional to ${ }^{1}$ ) is expected to occur for $r^{2} \sigma \cong k_{B} T$.

It is interesting to compare these results with the study by Davis and K wei, 31 who also observed a linear dependence with time. They demonstrated that a heterogeneous film of 50/50 PS/PVME cast from trichloroethylene can be converted into a homogeneous blend by heating to a temperature $30 \mathrm{~K}$ bel ow the LCST. The diameter of the spherical domains was found to decrease inversely with time, in a time period of $24 \mathrm{~h}$. Davis and Kwei used monodisperse PS with molecular weight equal to 37000 and PVME with an intrinsic viscosity of 0.42 in toluene at $25^{\circ} \mathrm{C}$. This blend composition was close to the critical composition.

The linear increase of the characteristic length with time is also predicted by the theory of Doi and Ohta ${ }^{32}$ that describes the rheology and dynamics of two immiscible fluid systems in the presence and absence of shear. When the interfacial tension is the physical mechanism for the relaxation of a phase-separated system, two effects are predicted: (i) the decrease of the interfacial area and (ii) the tendency to makethesystem isotropic. The latter means that the relaxation stops when the droplets of the dispersed phase become spherical. These two tendencies were observed in our experiments.

In support of the above arguments, where the driving force of phase separation is considered to be the interfacial tension and not the compositional changes, come our DSC and NMR results. The DSC results give a broad (and almost undetectable) $T_{g}$ for the PS-rich phase, while the $T_{g}$ of the PVME-rich phase is sharp and well-defined. This latter observation can be attributed to the high mobility of PVME. However, the DSC results, despite their inaccuracy, suggest that no significant compositional changes occur. This result is definitely supported by our NMR data. The ${ }^{1} \mathrm{H}$ line widths and WISE cross sections demonstrate that no major composition changes occur after $2 \mathrm{~h}$ from the onset of phase separation. The NMR data actually help to measure quite accurately the composition of the resulting phases, showing that after $2 \mathrm{~h}$ we have almost pure PVME and around 60\% PS in the PS-rich phase. Initially, this seemed like a paradox: Changes in the volume fraction of the matrix and dispersed phases were observed in the optical micrographs without composition changes in NMR and with a PS-rich matrix phase that covers almost $80 \%$ of the total picture area after $2 \mathrm{~h}$ while PS is only $20 \%$ by weight. The paradox was resolved by optically invisible dispersed PVME domains of diameter $\mathrm{d}>0.03 \mu \mathrm{m}$ (limit of spin diffusion) and smaller than $2 \mu \mathrm{m}$ (resolution limit of optical microscopy) that make part of the matrix phase in the micrographs, with a time dependence. These submicron domains were proven by our TEM micrographs, which show the existence of such small PVME domains. A schematic of the observed morphology, at different length scales, is presented in Figure 18.

Such dramatic morphological evolutions can be attributed to the large difference between the viscosities and the segmental mobilities of PS and PVME. When the viscosities and mobilities of the two components are similar, as in the case of a polybutadiene/polyisoprene (PB/PI) blend, ${ }^{33}$ the coarsening does not persist for an extended period but cessation of growth occurs, in agreement with the transnodal mechanism. ${ }^{34}$ More work on the role of the interfacial tension and the surface tension between the two phases is needed to 


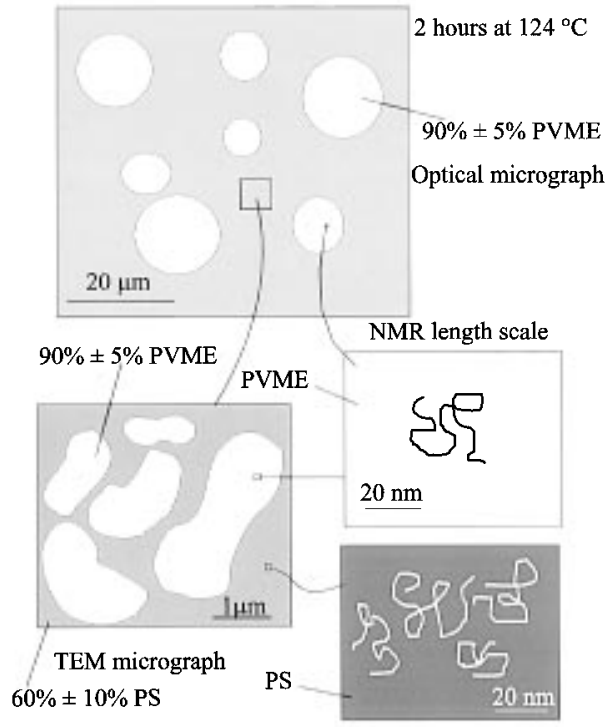

Figure 18. Schematic of the observed morphology, at different length scales. The micrograph that corresponds to optical microscopy presents a PS-rich matrix phase with PVME-rich phase inclusions. The TEM micrograph shows that the matrix phase is covered with dispersed PVME-rich domains with diameters smaller than $2 \mu \mathrm{m}$. Finally the NMR data quantify the phase compositions, showing the existence of a PVMErich phase with at least $90 \%$ PVME and a PS-rich phase with approximately $60 \%$ PS.

explain the morphological evolution. Knowledge of the spreading coefficients ${ }^{28}$ can also predict the tendency of the PS-rich phase to envelop the PVME-rich phase. Our experiments are moving toward this direction.

\section{Conclusions}

The evolution of the rheological behavior of a phaseseparated 20/80 PS/PVME polymer blend correlates well with the evolution of the phase-separated morphology. The phase separation results initially in a large increase in the low-frequency complex moduli which is attributed to the highly interconnected PVME-rich and PS-rich phases, formed during the spinodal decomposition. The subsequent decrease is the result of the loss of interconnectivity between the two phases due to the breakup and coarsening of the phase-separated domains. These morphol ogical changes are consistent with the theories of Siggia and Doi-Ohta.

The compositional changes suggested by the optical micrographs al one do not occur. NMR and TEM show submicron domains of 60/40 PS-rich and 5/95 PVMErich nanodomains al ready after $2 \mathrm{~h}$ of phase separation. The time scales observed with the various techniques are in agreement and prove that morphological and rheological changes occur for a long time (42 h) after the onset of phase separation. These slow long-time changes clearly demonstrate the dynamic character of the phase-separating polymer systems.
Acknowledgment. Support by NSF/MRSEC is greatly appreciated. We are grateful to Dr. Alan Waddon for his help with the optical microscopy. We are also grateful to Dr. R. S. Porter and to Dr. F. E. Karasz for giving access to the DSC instrument and the H offman modulation lenses, respectively.

\section{References and Notes}

(1) Prest, W. M., J r.; Porter, R. S. Polym. Sci., Polym. Phys. Ed. 1970, 8, 1897.

(2) Arendt, B. H.; Kannan, R. M.; Zewail, M.; Kornfield, J . A.; Smith, S. D. Rheol. Acta 1994, 33, 322.

(3) Katzen, D.; Reich, S. Europhys. Lett. 1993, 21, 55.

(4) Bank, M.; Leffingwell, J.; Thies, C. J . Polym. Sci., Polym. Phys. Ed. 1972, 10, 1097.

(5) Yang, H.; Shibayama, H.; Stein, R. S.; Shimuzu, N.; Hashimoto, T. Macromolecules 1986, 19, 1667.

(6) Kwei, T. K.; Nishi, T.; Roberts, R. F. Macromol ecules 1974, 7, 667.

(7) Mani, S.; Malone, M. F.; Winter, H. H. J . Rheol. 1992, 36, 1625.

(8) Katsaros, J . D.; Malone, M. F.; Winter, H. H. Polym. Eng. Sci. 1989, 29, 1434.

(9) Hashimoto, T.; Itakura, M.; Hasegawa, H. J . Chem. Phys. 1986, 85, 6118.

(10) Hashimoto, T.; Itakura, M.; Shimidzu, N. J . Chem. Phys. 1986, 85, 6773.

(11) Reich, S.; Cohen, Y. J . J . Polym. Sci., Polym. Phys. Ed. 1981, $19,1255$.

(12) Mours, M.; Winter, H. H. Rheol. Acta 1994, 33, 385.

(13) Hoffman, R. In Applied polymer light microscopy; Hemsley, D. A., Ed.; Elsevier Science Publishers: Amsterdam, 1989; p 151.

(14) Voigt-Martin, I. G.; Leister, K. H.; Rosenau R.; Koningsveld, R. J. Polym. Sci., Polym. Phys. Ed. 1986, 24, 723.

(15) Schaefer, J .; Stejskal, E. O.; Buchdahl, R. Macromolecules 1976, 10, 384.

(16) Schmidt-Rohr, K.; Clauss, J .; Spiess, H. W. Macromolecules $1992,25,3273$

(17) Dixon, W. T. J . Chem. Phys. 1982, 77, 1800.

(18) Stadler, R.; Freitas, L. L.; Krieger, V.; Klotz, S. Polymer 1988, $29,1643$.

(19) Kapnistos, M.; Vlassopoulos, D.; Anastasiadis, S. H. Europhys. Lett. 1996, 34, 513.

(20) Chambon, F. Ph.D. Thesis, University of Massachusetts at Amherst, 1986.

(21) Chambon, F.; Winter, H. H. J . Rheol. 1987, 31, 683.

(22) McCrone, W. C.; McCrone, L. B.; Delly, J . D. Polarized light microscopy; McCrone Research Institute: Chicago, 1993.

(23) Elemans, P. H. M.; J anssen, J . M. H.; Meijer, H. E. H. J . Rheol. 1990, 34, 1311.

(24) Tanaka, H.; Hayashi, T.; Nishi, T. J . Appl. Phys. 1986, 59, 653.

(25) Tanaka, H.; Hayashi, T.; Nishi, T. J . Appl. Phys. 1986, 59, 3627.

(26) Lin, A. A.; K wei, T. K.; Reiser, A. Macromolecules 1989, 22, 4112.

(27) Chu, C. W.; Dickinson, L. C.; Chien, C. W. J . Appl. Polym. Sci. 1990, 41, 2311.

(28) Reimann, R.-E.; Braun, H.; Wesse, J .; Schneider, H. A. New Polym. Mater. 1994, 4, 131.

(29) Ajji, A.; Choplin, L. Macromolecules 1991, 24, 5221.

(30) Siggia, E. D. Phys. Rev. A 1979 20, 595.

(31) Davis, D. D.; Kwei, T. K J . Polym. Sci., Part B: Polym. Phys. 1980, 18, 2337.

(32) Doi, M.; Ohta, T. J . Chem. Phys. 1991, 95, 1242.

(33) Läuger, J .; Lay, R.; Maas, S.; Gronski, W. Macromolecules 1995, 28, 7010.

(34) Kotnis, M. A.; Muthukumar, M. Macromolecules 1992, 25, 1716.

MA9701292 